\title{
Seizure recurrence after a 1st unprovoked seizure: An extended follow-up
}

\author{
W. Allen Hauser, MD; Stephen S. Rich, PhD; John F. Annegers, PhD; and V. Elving Anderson, PhD
}

\begin{abstract}
Article abstract-We followed 208 patients identified on the day of their 1st unprovoked seizure for a mean duration of 4 years. Seizures recurred in 64 . Recurrence risks were estimated to be $14 \%, 29 \%$, and $34 \%$ at 1,3 , and 5 years following the 1 st episode. A history of previous neurologic insult (remote symptomatic) was associated with a 2.5-fold increased risk of recurrence. Among idiopathic cases, a sibling with epilepsy, a generalized spike and wave EEG, or a history of acute symptomatic seizure increased risk for recurrence. Among remote symptomatic cases, status epilepticus, a prior acute symptomatic seizure, or Todd's paresis increased risk. Depending upon clinical features, recurrence risk at 5 years following a 1st seizure ranged from $23 \%$ to $80 \%$. Treatment with anticonvulsant medication was not associated with a decrease in recurrence risks.
\end{abstract}

NEUROLOGY 1990;40:1163-1170

The clinical approach to patients with a single unprovoked seizure remains controversial, ${ }^{1,2}$ at least in part due to conflicting information on their risk for further seizures. In an earlier report of prognosis in a cohort followed prospectively for a mean of 22 months, we estimated the overall risk of further seizures to be $27 \%$ at 3 years following the initial event. ${ }^{3}$ Here we report the results of an extended follow-up of this cohort. We modified case inclusion criteria to address criticism of our previous analysis. ${ }^{2,4}$ Follow-up is now more than 4 years, and a greater number of individuals have experienced recurrence, providing a larger effective sample size for more precise estimates of risk over a longer duration and increased power to evaluate potential factors predictive of recurrence.

Methods. Potential cases of 1st seizure were ascertained through a surveillance system to identify patients presenting for evaluation of newly identified seizures. This comprised review of hospital admissions, referrals to EEG laboratories, and referrals to the neurology and epilepsy clinics at 4 hospitals affiliated with the University of Minnesota. To facilitate patient identification (as well as to assure optimal medical care), emergency room staff agreed to obtain neurologic consultation on all new cases of seizures or epilepsy, and hospital admission from the emergency room was expedited for such cases.

Once informed consent was obtained, patients were screened to determine eligibility for a series of studies. Interviews were scheduled to obtain medical (and especially neurologic) history, as well as family and social history. The interview, requiring up to 3 hours, often could not be completed at the time of hospitalization in which case it was scheduled following discharge.

Most patients with newly identified unprovoked seizures (74\%) had experienced multiple seizure episodes prior to their 1st medical contact. The subjects of this report are restricted to those who (1) had experienced a definite unprovoked seizure as documented by an eyewitness, (2) on review of past history had not experienced a previous unprovoked seizure, and (3) were identified and had signed consent forms within 24 hours of the index seizure. In contrast to our previous report, we also required that (4) the interview be completed within 30 days of the index episode.

A 1st unprovoked seizure was defined as 1st seizure occurring without an identified proximate precipitant. Seizures occurring in the context of uncertain precipitants such as sleep deprivation or "stress" were considered unprovoked.

All seizures were categorized as partial or generalized onset based upon description of the seizure by an eyewitness according to criteria recommended by the ILAE. ${ }^{5}$ Generalized onset seizures by description were so categorized independent of findings on EEG or neurologic examination.

The patient's seizures were categorized by etiology ${ }^{3}$ as idiopathic (seizures in the absence of a historical insult thought to substantially increase the risk for unprovoked seizures) or remote symptomatic (seizures in individuals with a prior history of CNS insult known to substantially increase the risk for subsequent epilepsy, such as head trauma, ${ }^{6}$ cerebrovascular insult, ${ }^{7} \mathrm{CNS}$ infection, ${ }^{8}$ or static encephalopathy from birth manifest by mental retardation or cerebral palsy $\left.{ }^{9,10}\right)$. An unexplained localized abnormality identified in the diagnostic evaluation (eg, a reflex asymmetry on examination or focal slowing on EEG) did not modify this categorization but was treated as a potential confounder in the analysis. Individuals remained in the category of initial assignment by etiology and seizure type regardless of subsequent information since these are the data a clinician would have at the time of

From the G.H. Sergievsky Center (Dr. Hauser), College of Physicians and Surgeons, Columbia University, New York, NY; the Department of Pathology (Dr. Rich) and the Dight Laboratories (Dr. Anderson), University of Minnesota, Minneapolis, MN; and the School of Public Health (Dr. Annegers), University of Texas, Houston, TX. Supported in part by NS 1308-11.

Received June 27, 1989. Accepted for publication in final form January 10, 1990.

Address correspondence and reprint requests to Dr. W. Allen Hauser, 630 West 168th Street, New York, NY 10032. 
initial assessment. Thus, an idiopathic case in whom a CNS neoplasm was identified subsequent to initial evaluation (4 such cases were identified in this cohort) remained in the idiopathic category for analysis of recurrence risks.

The definition of single seizure includes status epilepticus (seizures continuing for 30 minutes or more without interruption) and clusters of seizures (2 or more) in the same 24-hour period; excluded are acute symptomatic seizures (seizures occurring in close temporal association-operationally within 1 week of an acute insult to the CNS - or at the time of an acute systemic metabolic or toxic insult). Because this was an observational study, there was no attempt to influence the practice of the treating physicians once patients had been identified. Thus, there was no standardization of treatment (if any) nor systematic monitoring of adequacy of therapy in those for whom anticonvulsant medication (AED) was recommended. We did obtain information on the use of AEDs from the patient as part of the follow-up information, but we judged these data to be insufficient to evaluate adequacy of treatment or compliance.

Five categories of EEG findings were evaluated: (1) generalized spike and wave (GSW) patterns regardless of symmetry, repetition, rate, regularity, or state of alertness during which they occurred; (2) focal epileptiform (sharp waves or focal spikes, multifocal spikes, bilateral homologous spikes; patterns of uncertain significance, such as 6-second spike and wave, small sharp spikes, 14 and 6 positive spikes, were not included in this category); (3) focal slowing (unilateral polymorphic or rhythmic slowing); (4) nonspecific slowing (increased theta or delta for age); and (5) normal. For the final analysis, focal slow and focal epileptiform groups were combined as were the normal and nonspecific groups.

Subjects were contacted at 6-month intervals for 2 years from date of the 1st seizure and annually thereafter through 1985. If a seizure occurred in the interval between the lst seizure and the time of the initial interview, the case remained in the study, and that date of recurrence was considered an end point. Follow-up was terminated for any of the following: (1) death, (2) the occurrence of an event usually associated with an increased risk for unprovoked seizures, such as head injury with loss of consciousness or an acute cerebrovascular insult, or (3) request by the patient to terminate participation in the follow-up study.

Potential misclassification (ie, 1st seizures as recurrent seizure or vice versa) was evaluated by comparing hospital records with study interview forms for a random sample of 200 of the 645 patients classified as newly diagnosed epilepsy (recurrent unprovoked seizures) and all 208 patients classified as 1st seizures. The hospital records were reassessed to identify 1st seizure cases inappropriately classified as epilepsy because of a recurrent seizure between the index 1st seizure and interview. No such cases were found. Rather, our review identified 13 cases diagnosed as a 1st seizure in hospital records who, based upon our independent study interview, clearly had experienced previous unprovoked seizures (usually complex partial) prior to the index seizure. Had we relied on hospital records for case ascertainment, these 13 cases of epilepsy would have been included as 1st seizures.

Analytic procedures. The cumulative risks of recurrence were determined by life-table methods, with event defined as an unprovoked seizure recurrence. ${ }^{11,12}$ These methods take into account the length of follow-up in each individual. The computed risks, therefore, represent the risk of recurrence conditional on surviving seizure-free through the specified time (follow-up) interval. Univariate analysis (Kaplan-Meier survival curves) for each variable relates the cumulative percent recurrence to the time after 1 st seizure. ${ }^{13}$ For this analysis recurrence in those with the factor in question is compared with those without, irrespective of the presence of competing risk factors in either group. The proportional hazards model was used to estimate univariate and multivariate rate ratios, defined as the ratio of the rate of seizure recurrence in the group of patients with a given factor to the rate of seizure recurrence without that factor (eg, remote symptomatic versus idiopathic). ${ }^{14}$ Expected risks for specific factors were derived by adding the rates of recurrence estimated from the subgroup of patients with no statistically significant risk factors (baseline) to the risk estimate of the factor in question. Age was analyzed both as a continuous and as a discrete variable. Findings were considered significant when the bounds of the $95 \%$ confidence interval did not include unity.

Results. Of 1,167 newly recognized seizure patients included in the larger series, 208 were identified with a 1st unprovoked seizure, recruited within 24 hours, and had their interviews completed within 30 days. These patients were followed prospectively a total of 853 person-years. Sixty-five subjects included in the initial report ${ }^{3}$ but not interviewed within 30 days of the index event are excluded in this analysis, while another 29 1st seizure cases identified and recruited after the date of closure for the earlier analyses are included. Although 31 patients were lost to follow-up, almost all contributed at least 2 years to the analyses. A total of 20 subjects were withdrawn because of death (8), an intervening CNS insult such as head trauma thought to increase the risk for seizures (8), or patient request to terminate our follow-up contacts (4). Recurrent unprovoked seizures during the follow-up interval were identified in 64 cases.

Overall risk for seizure recurrence-Kaplan-Meier estimates (figure 1). For the total group, recurrence was estimated to be $14 \%, 29 \%$, and $34 \%$ at 1,3 , and 5 years, respectively, following the 1st convulsive episode. Risk was estimated to be $39 \%$ by 7 years following the 1st episode and, among the 26 patients followed more than 7 years (contributing 15.9 person-years to the analysis), there were no further recurrences. The recurrence risk was not constant over the 7 years of follow-up. The risk was highest in the 1st year following the initial seizure and tended to decrease with increasing time interval from the index seizure.

There were 3 subjects who had recurrent episodes in association with abrupt discontinuation of alcoholic beverages. These individuals were excluded from more detailed analyses, although neither the recurrence rates nor the estimates of recurrence risk for the various subgroups analyzed were altered by their exclusion.

Etiology (idiopathic versus remote symptomatic 1st seizure). A history of an identified insult to the CNS (ie, stroke, infection, head trauma) was an important predictor of seizure recurrence. The recurrence risk for the 149 patients with an idiopathic seizure was estimated to be $10 \%, 24 \%$, and $29 \%$ at 1,3 , and 5 years, respectively, following the 1st convulsive episode (figure 2). This contrasts sharply with recurrence risks of $26 \%, 41 \%$, and $48 \%$ at 1,3 , and 5 years among the 59 patients with a remote symptomatic seizure.

Different predictors of recurrence were identified in those with remote symptomatic seizures when compared with those with idiopathic seizures, so results of Kaplan-Meier analyses are presented separately. 


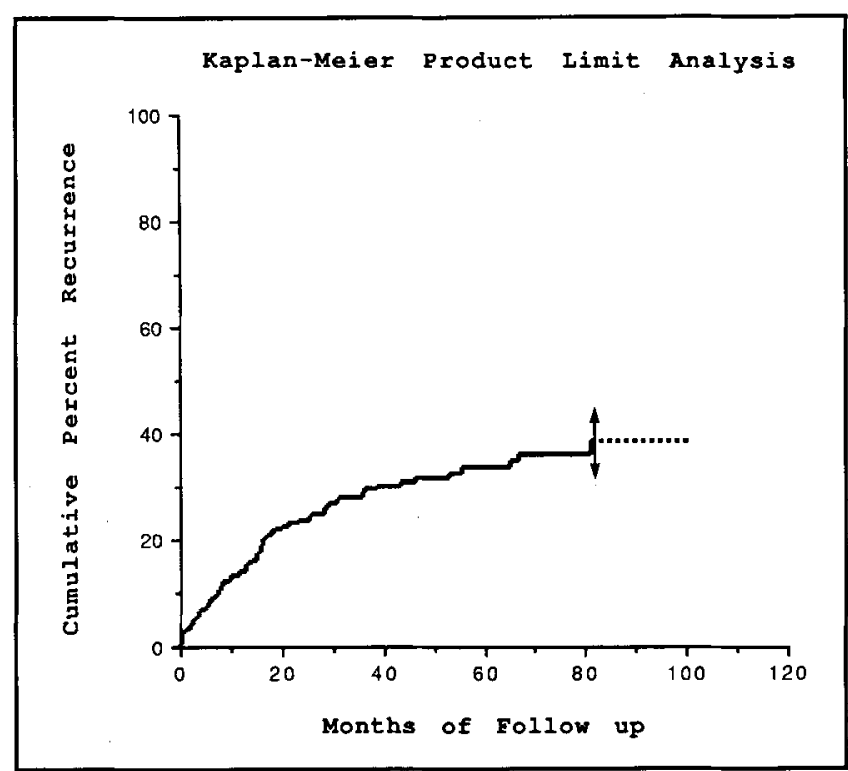

Figure 1. Recurrence of seizures among 208 patients after a 1st unprovoked seizure. In this and subsequent figures arrows identify standard errors.

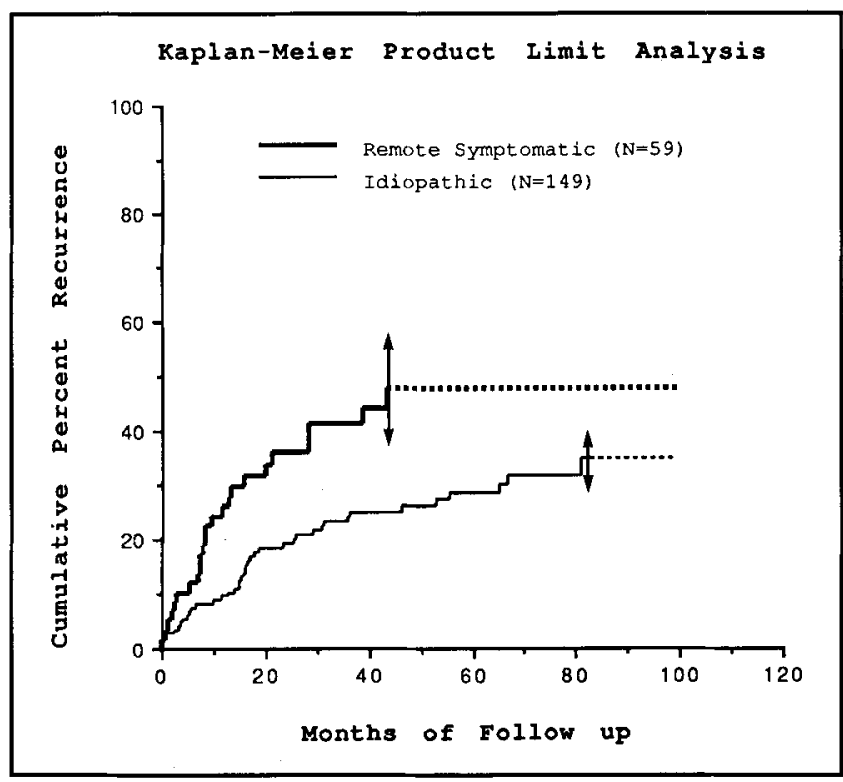

Figure 2. Recurrence of seizures among 149 patients with idiopathic seizures and 59 with remote symptomatic seizures.

Idiopathic cases. Among idiopathic cases, significantly increased recurrence risks were observed in subjects with a sibling with epilepsy (figure $3 \mathrm{~A}$ ), in subjects with GSW (figure 3B), and in subjects with histories of prior acute symptomatic seizures (figure $3 \mathrm{C}$ ). For those with an affected sibling, the recurrence risk was $29 \%$ at 1 year and $46 \%$ at 5 years compared with $7 \%, 22 \%$, and $27 \%$ at 1,3 , and 5 years for those without an affected sibling. For those with GSW, recurrence risks were $15 \%$ at 1 year and $58 \%$ at 5 years compared with $9 \%, 21 \%$, and $26 \%$ at 1,3 , and 5 years for those without. For those with a history of prior acute symptomatic seizures (primarily febrile seizures), risk was $10 \%$ at 1 year and $39 \%$
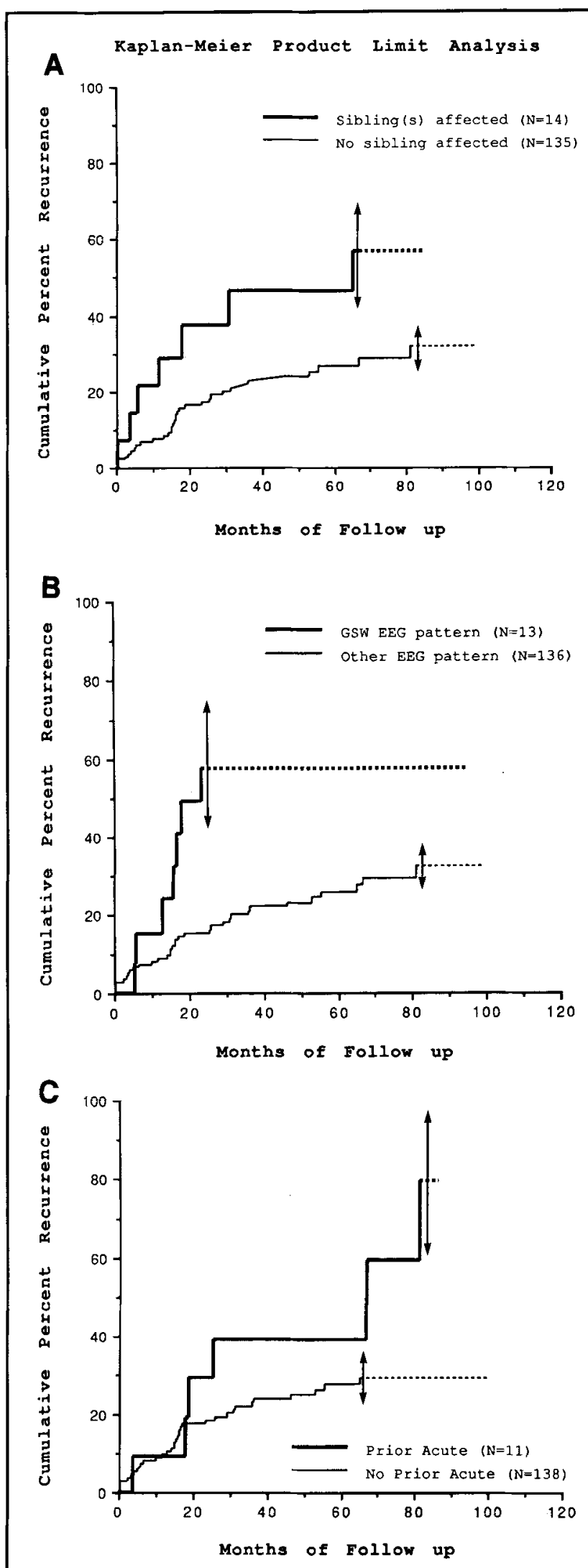

Figure 3. (A) Recurrence among patients with idiopathic seizures with and without an affected sibling.

(B) Recurrence among patients with idiopathic seizures with and without GSW EEG pattern. (C) Recurrence among patients with idiopathic seizures with and without a prior acute event. 


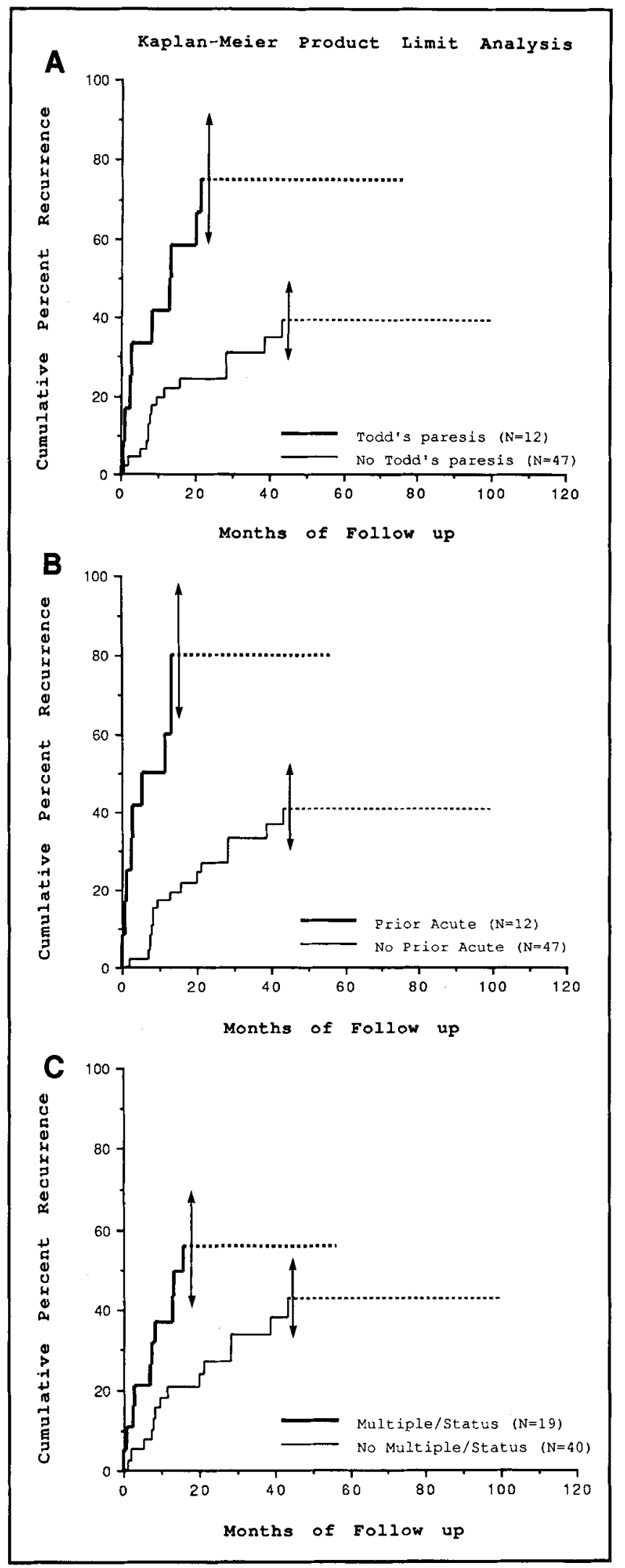

Figure 4. (A) Recurrence among patient with remote symptomatic seizures with and without Todd's paresis. (B) Recurrence among patients with remote symptomatic seizures with and without a prior acute event.

(C) Recurrence among patients with remote symptomatic seizures with and without multiple seizures or status epilepticus. at 5 years compared with $10 \%, 23 \%$, and $27 \%$ at 1,3 , and 5 years for those without.

Possible risk factors found not to be significant predictors of recurrence for those with a 1st idiopathic seizure included abnormal neurologic examination, abnormal EEG other than GSW, status epilepticus or multiple seizures, age, gender, seizure type, Todd's paresis, history of epilepsy in parents, and history of acute symptomatic seizures in any 1st-degree relative.

Remote symptomatic cases. Among remote symptomatic cases, significantly increased recurrence risk was observed in those with Todd's paresis (figure 4A), subjects with prior acute symptomatic seizures (figure 4B), and subjects whose index episode was characterized by status epilepticus or multiple seizures (figure 4C). Recurrence risk after the index episode for those with Todd's paresis was $41 \%$ at 1 year and $75 \%$ at 5 years compared with $22 \%, 31 \%$, and $39 \%$ at 1,3 , and 5 years for those without. For those with a prior acute seizure, the risk was $60 \%$ at 1 year and $80 \%$ at 5 years compared with $17 \%, 33 \%$, and $41 \%$ at 1,3 , and 5 years for those without. In those with status epilepticus or multiple seizures, recurrence risk was $37 \%$ at 1 year and $56 \%$ at 3 and 5 years compared with $21 \%, 34 \%$, and $43 \%$ at 1,3 , and 5 years for those without.

Among subjects with remote symptomatic seizures, no significant increased risk of recurrence was associated with having a 1st-degree relative with epilepsy or seizures, abnormal neurologic examination, seizure type, age, EEG finding, or gender.

Rate ratios for recurrence. The univariate rate ratios for the total group, for those with idiopathic seizures, and for remote symptomatic seizures are presented separately (table 1). For the total group, factors associated with a significantly increased rate ratio for recurrence included etiology, Todd's paresis, having an affected sibling, a prior acute seizure, multiple seizures/status epilepticus, and the presence of a GSW EEG pattern.

For the idiopathic group, a GSW EEG pattern, a history of an acute symptomatic seizure, or an affected sibling were again significant predictors of increased recurrence risk. The rate ratio was between 2 and 3 for each. The rate ratios were increased (although not significantly) for those with Todd's paresis, multiple seizures/status, and an abnormal neurologic examination. Sex, age, and seizure type were not associated with increased rate ratios.

For those in the remote symptomatic group, Todd's paresis, multiple seizures/status, and a history of an acute symptomatic seizure were associated with significantly elevated rate ratios. Rate ratios were elevated (but not significantly) for those with a sibling with epilepsy or an abnormal neurologic examination. Age, sex, and seizure type were not associated with increased rate ratios. When all factors significant in the univariate analysis were entered into a multivariate Cox analysis (table 1), the same predictors, with the exception of multiple seizures/status epilepticus, remained significant for the total group, although the magnitudes of the effects were slightly altered.

To evaluate possible interaction with duration of follow-up, rate ratios for recurrence were separately 
Table 1. Univariate rate ratios and multivariate rate ratios ( $95 \%$ confidence intervals) as estimated by Cox regression analysis

\begin{tabular}{|c|c|c|c|c|c|c|}
\hline \multirow{2}{*}{$\begin{array}{l}\text { Variable } \\
\text { in model }\end{array}$} & \multicolumn{2}{|c|}{$\begin{array}{c}\text { Total group } \\
(\mathbf{N}=\mathbf{2 0 8}) \\
\end{array}$} & \multicolumn{2}{|c|}{$\begin{array}{c}\text { Idiopathic } \\
(N=149) \\
\end{array}$} & \multicolumn{2}{|c|}{$\begin{array}{c}\text { Remote } \\
(\mathbf{N}=\mathbf{5 9}) \\
\end{array}$} \\
\hline & Univariate & Multivariate & Univariate & Multivariate & Univariate & Multivariate \\
\hline $\begin{array}{l}\text { Etiology } \\
\text { (remote symptomatic) }\end{array}$ & $\begin{array}{c}1.95^{*} \\
(1.27,2.99)\end{array}$ & $\begin{array}{c}2.55 \dagger \\
(1.44,4.51)\end{array}$ & - & - & - & - \\
\hline Todd's paresis & $\begin{array}{c}1.94 \dagger \\
(1.21,3.13)\end{array}$ & $\begin{array}{c}1.94 \dagger \\
(1.18,4.51)\end{array}$ & $\begin{array}{c}1.27 \\
(0.64,2.53)\end{array}$ & $\begin{array}{c}1.41 \\
(0.69,2.89)\end{array}$ & $\begin{array}{c}3.31^{*} \\
(1.64,6.65)\end{array}$ & $\begin{array}{c}2.93^{*} \\
(1.31,6.54)\end{array}$ \\
\hline Sibling affected & $\begin{array}{c}2.29^{*} \\
(1.30,4.03)\end{array}$ & $\begin{array}{c}1.99 \dagger \\
(1.09,3.60)\end{array}$ & $\begin{array}{c}2.47 \dagger \\
(1.25,4.91)\end{array}$ & $\begin{array}{c}2.51 \dagger \\
(1.23,5.11)\end{array}$ & $\begin{array}{c}1.97 \\
(0.71,5.43)\end{array}$ & $\begin{array}{c}0.95 \\
(0.30,3.02)\end{array}$ \\
\hline $\begin{array}{l}\text { Multiple seizures/ } \\
\text { status epilepticus }\end{array}$ & $\begin{array}{c}1.79 \dagger \\
(1.12,2.86)\end{array}$ & $\begin{array}{c}1.47 \\
(0.87,2.47)\end{array}$ & $\begin{array}{c}1.26 \\
(0.64,2.51)\end{array}$ & $\begin{array}{c}1.43 \\
(0.69,2.96)\end{array}$ & $\begin{array}{c}2.09 \dagger \\
(1.05,4.16)\end{array}$ & $\begin{array}{c}1.19 \\
(0.49,2.89)\end{array}$ \\
\hline Abnormal neuro exam & $\begin{array}{c}1.01 \\
(0.64,1.58)\end{array}$ & $\begin{array}{c}1.72 \\
(0.96,3.11)\end{array}$ & $\begin{array}{c}1.62 \\
(0.68,3.85)\end{array}$ & $\begin{array}{c}1.35 \\
(0.56,3.27)\end{array}$ & $\begin{array}{c}2.09 \\
(0.91,4.20)\end{array}$ & $\begin{array}{c}2.10 \\
(0.98,4.46)\end{array}$ \\
\hline $\begin{array}{l}\text { Seizure type } \\
\text { (partial vs } \\
\text { generalized) }\end{array}$ & $\begin{array}{c}0.98 \\
(0.84,1.15)\end{array}$ & $\begin{array}{c}1.04 \\
(0.81,1.23)\end{array}$ & $\begin{array}{c}1.05 \\
(0.85,1.29)\end{array}$ & $\begin{array}{c}1.09 \\
(0.87,1.37)\end{array}$ & $\begin{array}{c}0.96 \\
(0.82,1.22)\end{array}$ & $\begin{array}{c}1.00 \\
(0.77,1.29)\end{array}$ \\
\hline Prior acute seizures & $\begin{array}{c}3.33^{*} \\
(2.02,5.49)\end{array}$ & $\begin{array}{c}2.69^{*} \\
(1.56,4.62)\end{array}$ & $\begin{array}{c}2.19 \dagger \\
(1.05,4.53)\end{array}$ & $\begin{array}{c}1.70 \\
(0.78,3.71)\end{array}$ & $\begin{array}{c}4.82^{*} \\
(2.29,10.14)\end{array}$ & $\begin{array}{c}4.75^{*} \\
(1.82,12.42)\end{array}$ \\
\hline GSW EEG pattern & $\begin{array}{c}1.93 \dagger \\
(1.00,3.73)\end{array}$ & $\begin{array}{c}2.16 \dagger \\
(1.07,4.38)\end{array}$ & $\begin{array}{c}2.84 \dagger \\
(1.43,5.66)\end{array}$ & $\begin{array}{c}2.69 \dagger \\
(1.28,5.67)\end{array}$ & $\ddagger$ & $\ddagger$ \\
\hline $\begin{array}{l}* p \leq 0.01 . \\
\dagger p \leq 0.05 . \\
\ddagger \text { Failure to converge in } \\
\text { ( ) } 95 \% \text { confidence interv }\end{array}$ & ood due to & (a) & . & & & \\
\hline
\end{tabular}

evaluated for recurrence in the 1st year and for recurrence after that time. These analyses revealed little change in the ordering of rate ratios for individual factors, although the magnitude of the effect for individual factors was changed.

Treatment with continuous AED was recommended for $80 \%$ of cases. Medication could not be shown to favorably affect recurrence rate ratios and was in fact associated with a modest but nonsignificant increase in risk.

Modeling. We have used the rate ratios derived from the multivariate analysis to model predicted recurrence in idiopathic and remote symptomatic cases (table 2). For an idiopathic case without an affected sibling, with no history of acute symptomatic seizures, no status or multiple seizures at presentation, no evidence of Todd's paresis, and without a GSW EEG pattern (ie, baseline), the predicted risk for recurrence by 5 years following the initial episode is $20.6 \%$. The predicted 5-year risk increases to $45 \%$ for those with an affected sibling, $48 \%$ with a GSW EEG pattern, and $34.6 \%$ with a history of acute seizure. For the remote symptomatic cases with no other identified factors, observed recurrence risk at 4 years was $36.9 \%$ compared with a predicted risk of $53.3 \%$ for those with status/multiple seizures, $83.8 \%$ for those with Todd's, and $95.3 \%$ with prior acute symptomatic seizures.

Discussion. In the present study we find a modest overall risk for recurrence following a 1st seizure: $34 \%$ at 5 years. Studies since 1981 have reported seizure recurrence following 1st seizure from $31 \%$ to $71 \%{ }^{15-21}$ (table $3)$. Such variance is not surprising, since basic study design, characteristics of populations studied, mean duration of follow-up, and methods of statistical analysis differ substantially. Some of these differences are discussed below.

Referral versus general population studies. A 1st seizure in the United States is seldom a reason for referral to a specialist; rather, initial evaluation is undertaken by the pediatrician, general practitioner, internist, or emergency room physician. Only cases perceived as being more complex will have initial referral to a specialty clinic. Since factors associated with referral may also be factors that predict seizure recurrence, studies dealing with referral populations start with a unique subgroup of 1st seizure patients who may be at exceptionally high risk for recurrence.

In the present study, which identified cases at the initial point of medical contact, $25 \%$ of idiopathic cases without any risk factor experienced a recurrence at 5 years following a 1st seizure. Five-year recurrence risk was considerably higher for other subgroups, reaching $80 \%$ in those with a remote symptomatic 1st seizure and a history of acute symptomatic seizures (table 2). Thus, wide variation in total recurrence risk might be seen depending on the distribution of risk factors in a study population.

Similar referral bias may apply to studies depending upon referral to EEG laboratories. ${ }^{21}$ Physicians may not wish to put patients through the cost or inconvenience of the testing or the patient may not keep an appointment even when scheduled. Thus, in the United Kingdom, where socialized medicine programs remove financial impediment to referral for EEG evaluation 
Table 2. Observed and expected rates of recurrence in subgroups based upon univariate rate ratios as applied to observed baseline rates of recurrence

\begin{tabular}{|c|c|c|c|c|c|}
\hline \multirow{2}{*}{$\begin{array}{l}\text { Risk } \\
\text { factors }\end{array}$} & \multicolumn{5}{|c|}{ Months of follow-up } \\
\hline & 12 & 24 & 36 & 48 & 60 \\
\hline Baseline* $(\mathrm{N}=78)$ & $7.0 \%$ & $13.0 \%$ & $16.7 \%$ & $19.0 \%$ & $20.6 \%$ \\
\hline $\begin{array}{l}\text { Idiopathic with an affected sibling } \\
(\mathrm{N}=10)\end{array}$ & $\begin{array}{r}20.0 \% \dagger \\
(15.3 \%)\end{array}$ & $\begin{array}{c}20.0 \% \\
(30.4 \%)\end{array}$ & $\begin{array}{l}31.4 \% \\
(38.3 \%)\end{array}$ & $\begin{array}{c}31.4 \% \\
(41.4 \%)\end{array}$ & $\begin{array}{l}45.1 \% \\
(45.5 \%)\end{array}$ \\
\hline $\begin{array}{l}\text { Idiopathic with a GSW EEG pattern } \\
(\mathrm{N}=10)\end{array}$ & $\begin{array}{c}10.0 \% \\
(16.5 \%)\end{array}$ & $\begin{array}{c}55.0 \% \\
(32.5 \%)\end{array}$ & $\begin{array}{c}55.0 \% \\
(40.7 \%)\end{array}$ & $\begin{array}{c}55.0 \% \\
(43.9 \%)\end{array}$ & $\begin{array}{l}55.0 \% \\
(48.2 \%)\end{array}$ \\
\hline $\begin{array}{l}\text { Idiopathic with prior acute seizures } \\
(\mathrm{N}=7)\end{array}$ & $\begin{array}{c}0.0 \% \\
(11.0 \%)\end{array}$ & $\begin{array}{c}14.3 \% \\
(22.5 \%)\end{array}$ & $\begin{array}{c}28.6 \% \\
(28.7 \%)\end{array}$ & $\begin{array}{l}28.6 \% \\
(31.3 \%)\end{array}$ & $\begin{array}{l}52.4 \% \\
(34.6 \%)\end{array}$ \\
\hline $\begin{array}{l}\text { Idiopathic with abnormal examination } \\
(\mathrm{N}=13)\end{array}$ & $\begin{array}{c}9.3 \% \\
(10.0 \%)\end{array}$ & $\begin{array}{l}15.4 \% \\
(18.6 \%)\end{array}$ & $\begin{array}{c}20.3 \% \\
(23.9 \%)\end{array}$ & $\begin{array}{l}23.0 \% \\
(27.2 \%)\end{array}$ & $\begin{array}{l}25.8 \% \\
(29.5 \%)\end{array}$ \\
\hline $\begin{array}{l}\text { Idiopathic with abnormal examination } \\
\text { and } 1 \text { or more other features }(\mathrm{N}=26)\end{array}$ & $14.3 \%$ & $14.3 \%$ & $22.7 \%$ & $22.7 \%$ & $22.7 \%$ \\
\hline $\begin{array}{l}\text { Two or more features with normal examination } \\
(\mathrm{N}=5)\end{array}$ & $40.0 \%$ & $40.0 \%$ & $70.0 \%$ & $70.0 \%$ & $70.0 \%$ \\
\hline $\begin{array}{l}\text { Remote symptomatic with no other } \\
\text { significant factors }(\mathrm{N}=32)\end{array}$ & $\begin{array}{c}15.9 \% \\
(19.7 \%)\end{array}$ & $\begin{array}{c}15.9 \% \\
(37.9 \%)\end{array}$ & $\begin{array}{c}24.8 \% \\
(47.1 \%)\end{array}$ & $\begin{array}{c}36.9 \% \\
(50.2 \%)\end{array}$ & $\begin{array}{c}36.9 \% \\
(54.1 \%)\end{array}$ \\
\hline $\begin{array}{l}\text { Remote symptomatic with Todd's paresis } \\
(\mathrm{N}=4)\end{array}$ & $\begin{array}{c}0.0 \% \\
(48.8 \%)\end{array}$ & $\begin{array}{c}25.0 \% \\
(67.5 \%)\end{array}$ & $\begin{array}{c}50.0 \% \\
(79.0 \%)\end{array}$ & $\begin{array}{c}50.0 \% \\
(83.8 \%)\end{array}$ & \\
\hline $\begin{array}{l}\text { Remote symptomatic with prior acute } \\
\text { symptomatic seizures }(\mathrm{N}=3)\end{array}$ & $\begin{array}{l}100.0 \% \\
(67.6 \%)\end{array}$ & $\begin{array}{l}100.0 \% \\
(89.4 \%)\end{array}$ & $\begin{array}{l}100.0 \% \\
(92.8 \%)\end{array}$ & $\begin{array}{l}100.0 \% \\
(95.3 \%)\end{array}$ & \\
\hline $\begin{array}{l}\text { Remote symptomatic with multiple seizures } \\
\text { or status epilepticus }(\mathrm{N}=8)\end{array}$ & $\begin{array}{l}25.0 \% \\
(24.4 \%)\end{array}$ & $\begin{array}{c}37.5 \% \\
(37.4 \%)\end{array}$ & $\begin{array}{c}37.5 \% \\
(47.8 \%)\end{array}$ & $\begin{array}{c}37.5 \% \\
(53.3 \%)\end{array}$ & \\
\hline Two or more factors $(\mathrm{N}=12)$ & $41.7 \%$ & $75.0 \%$ & $75.0 \%$ & $75.0 \%$ & \\
\hline
\end{tabular}

(but may introduce other difficulties such as inordinate delay in scheduling the test), only $74 \%$ of patients with seizures or epilepsy identified through hospital records and files of general practitioners had an EEG tracing at any time, much less at time of initial diagnosis. ${ }^{22}$ In a study in the United States, failure to keep a scheduled EEG appointment was associated with lower recurrence risk. ${ }^{20}$

Case definition. Risk estimates will vary, depending on the sensitivity and specificity of the inclusion criteria. Our case definition (see Methods) is highly specific (all cases identified are indeed 1st seizures) but not necessarily sensitive (1st seizures not coming to an emergency room or not witnessed, or not interviewed within 30 days are excluded).

Misclassification. Most individuals with newly ascertained unprovoked seizures will have experienced multiple seizure episodes by the time of 1st medical evaluation ( $74 \%$ in the series from which the present cohort was derived). Studies that rely on histories not specifically addressing the question of prior seizure occurrence (such as record reviews) may include a substantial proportion of cases identified as 1st seizures that are, in fact, recurrent.

In reviewing a sample of hospital records of recurrent seizure cases from which the present series was derived, 7\% (all with generalized tonic clonic seizures) were labeled as 1st seizures by house staff and neurology attending physicians but had actually experienced prior unprovoked (usually complex partial) seizures. This history of prior seizures was identified only through detailed questionnaires administered by trained interviewers. Since seizure recurrence among those with 2 or more unprovoked seizures is $70 \%$ or higher, ${ }^{23}$ inclusion of such cases would have substantially raised the estimate of risk for recurrence.

Time of ascertainment. Even when groups of patients are followed prospectively, recurrence may be determined either from time of 1st visit or time of 1st seizure. The invariable lag between the occurrence of a seizure and referral or visit to a referral center means that some patients will have experienced recurrence prior to being seen and thus will be ineligible for studies dating recurrence from 1st visit. Exclusion of cases with early recurrence may underestimate the recurrence risk. Hopkins et al ${ }^{18}$ found a short interval between 1st seizure and 1st visit to the referral center to be a predictor of recurrence. Alternatively, studies of referral population which backdate follow-up to time of 1st seizure may overestimate recurrences since seizure recurrence may be a major factor in a patient's decision to keep an appointment.

Retrospective ascertainment such as in The Collaborative Perinatal Project (prospective for prenatal and perinatal factors, but retrospective for seizure occurrence and recurrence) is even more likely to overesti- 
Table 3. Seizure recurrence after a 1st unprovoked seizure: Summary of results of studies published since 1980

\begin{tabular}{|c|c|c|c|c|c|c|c|c|c|c|c|}
\hline Study & $\begin{array}{l}\text { Study } \\
\text { design }\end{array}$ & $\begin{array}{l}\text { Source } \\
\text { of class }\end{array}$ & Population & $\begin{array}{c}\text { Recurrence } \\
\text { risk }\end{array}$ & $\begin{array}{c}\text { Seizure } \\
\text { type }\end{array}$ & $\begin{array}{l}\text { Interim from } \\
\text { 1st seizure to } \\
\text { study entry }\end{array}$ & $\begin{array}{c}\text { Seizure } \\
\text { verification }\end{array}$ & $\begin{array}{l}\text { Analytic } \\
\text { methods }\end{array}$ & Risk factors & $\begin{array}{l}\text { Nonrisk } \\
\text { factors }\end{array}$ & $\begin{array}{c}\text { Proportion } \\
\text { treated }\end{array}$ \\
\hline Elwes15 & $?$ & $\begin{array}{l}\text { Specialty } \\
\text { clinic } \\
\text { referrals }\end{array}$ & Adults & $71 \%$ at 3 yrs & Generalized & Within $24 \mathrm{hrs}$ & $\begin{array}{l}\text { Patient } \\
\text { interview }\end{array}$ & Actuarial & - & & None \\
\hline Annegers 16 & $\begin{array}{l}\text { Historical } \\
\text { cohort }\end{array}$ & $\begin{array}{l}\text { Medical } \\
\text { records- } \\
\text { emergency } \\
\text { hospital } \\
\text { admission or } \\
\text { outpatient }\end{array}$ & All ages & $48 \%$ at $3 \mathrm{yrs}$ & All types & Within 24 hrs & $\begin{array}{l}\text { Chart } \\
\text { review }\end{array}$ & $\begin{array}{l}\text { Actuarial } \\
\text { proportional } \\
\text { hazards }\end{array}$ & $\begin{array}{l}\text { EEG etiology, } \\
\text { sz type, } \\
\text { abnormal } \\
\text { neuro exam }\end{array}$ & Sex, age, AED & $60 \%$ \\
\hline Hirtz17 & $\begin{array}{l}\text { Historical } \\
\text { cohort }\end{array}$ & $\begin{array}{l}\text { Annual } \\
\text { interview }\end{array}$ & $\begin{array}{l}\text { Children } \\
\text { under age } 7\end{array}$ & $69 \%$ by age 7 & $\begin{array}{l}\text { All types } \\
\text { (includes } \\
\text { acute } \\
\text { symptomatic) }\end{array}$ & $\begin{array}{l}\text { Up to } 1 \mathrm{yr} \\
\text { (at time of } \\
\text { annual } \\
\text { history } \\
\text { update) }\end{array}$ & $\begin{array}{l}\text { Parent } \\
\text { interview }\end{array}$ & Proportions & $\begin{array}{l}\text { Sz type, } \\
\text { neonatal sz }\end{array}$ & $\begin{array}{l}\text { Febrile sz, } \\
\text { neurologic } \\
\text { exam, family } \\
\text { history of } \\
\text { afebrile sz, } \\
\text { AED }\end{array}$ & $27 \%$ \\
\hline Hopkins18 & Prospective & $\begin{array}{l}\text { Specialty } \\
\text { clinic } \\
\text { referral }\end{array}$ & Adults & $52 \%$ at $3 \mathrm{yrs}$ & All types & Up to 8 wks & $\begin{array}{l}\text { Patient } \\
\text { interview }\end{array}$ & Actuarial & $\begin{array}{l}\text { Interval to } \\
\text { referral, time } \\
\text { of day, } \\
\text { family history?, } \\
\text { febrile sz? }\end{array}$ & $\begin{array}{l}\text { Sz type, } \\
\text { age, CT, EEG?, } \\
\text { AED }\end{array}$ & "Occasional" \\
\hline Cleland19 & Retrospective & $\begin{array}{l}\text { Specialty } \\
\text { clinic } \\
\text { referral }\end{array}$ & Adults & $39 \%$ - crude & All types & Up to $61 / 2 \mathrm{wks}$ & $\begin{array}{l}\text { Patient } \\
\text { interview }\end{array}$ & Proportions & EEG & & Unknown \\
\hline Shinnar20 & Prospective & $\begin{array}{l}\text { Emergency } \\
\text { room } \\
\text { contacts }\end{array}$ & $\begin{array}{l}\text { Children } \\
\text { (up to 18) }\end{array}$ & $29 \%$ at $2 \mathrm{yrs}$ & All types & $\begin{array}{l}\text { At time of } \\
\mathrm{sz}\end{array}$ & $\begin{array}{l}\text { Patient } \\
\text { (parent) } \\
\text { interview }\end{array}$ & $\begin{array}{l}\text { Actuarial } \\
\text { proportional } \\
\text { hazards }\end{array}$ & $\begin{array}{l}\text { Family history } \\
\text { of afebrile sz, } \\
\text { EEG, etiology. } \\
\text { acute sz, } \\
\text { sz type }\end{array}$ & $\begin{array}{l}\text { Age, sex, status } \\
\text { epilepticus }\end{array}$ & $5 \%$ \\
\hline Camfield21 & Prospective & $\begin{array}{l}\text { EEG lab } \\
\text { referrals }\end{array}$ & Children & $51 \%$ - crude & All types & Unknown & Chart review & Proportions & $\begin{array}{l}\text { EEG, abnormal } \\
\text { neuro exam, } \\
\text { sz type }\end{array}$ & $\begin{array}{l}\text { Wake, sleep, } \\
\text { febrile sz, } \\
\text { AED }\end{array}$ & $68 \%$ \\
\hline $\begin{array}{l}\text { Present } \\
\text { study }\end{array}$ & Prospective & $\begin{array}{l}\text { Emergency } \\
\text { room } \\
\text { contacts }\end{array}$ & All ages & $30 \%$ at 3 yrs & All types & $\begin{array}{l}\text { Within } 24 \\
\text { hrs of sz }\end{array}$ & $\begin{array}{l}\text { Patient or } \\
\text { parent } \\
\text { interview }\end{array}$ & $\begin{array}{l}\text { Actuarial, } \\
\text { proportional } \\
\text { hazards }\end{array}$ & $\begin{array}{l}\text { EEG, etiology, } \\
\text { family history } \\
\text { of afebrile } \\
\text { sz, acute } \\
\text { symptomatic sz, } \\
\text { Todd's paresis, } \\
\text { status epilepticus, } \\
\text { multiple sz }\end{array}$ & $\begin{array}{l}\text { Age, sex, AED, } \\
\text { gz type }\end{array}$ & $80 \%$ \\
\hline $\begin{array}{rr}\text { sz } & \text { Seiz } \\
\text { AED } & \text { Pres }\end{array}$ & $\begin{array}{l}\text { are(s). } \\
\text { scription of anti }\end{array}$ & iepileptic drug. & & $\therefore$ & & & & & & & \\
\hline
\end{tabular}

mate recurrence, since the more seizures an individual experiences, the more likely he or she is to come to medical attention.

Risk factors for recurrence. Despite major differences in overall recurrence risk reported from various studies (perhaps due to differences elucidated above), some consistency in factors associated with recurrence has been observed (table 3). In most studies presenting data, recurrence was significantly higher among cases meeting our criteria for remote symptomatic seizures when compared with idiopathic seizures..$^{16,20}$

An abnormal EEG has been a consistent predictor of recurrence, although there has not been agreement on the nature of the predictive EEG abnormality. In the present study, only a GSW pattern was associated with an increased recurrence risk. Other studies report only a focal EEG ${ }^{21}$ or any abnormal EEG ${ }^{16,20}$ to be predictive of recurrence.

We found that a history of acute symptomatic seizure was associated with an increased risk for recur- rence. Elevated risks for children ${ }^{20}$ and possibly adults ${ }^{17}$ with prior febrile seizures have been reported. A sibling with epilepsy was predictive of recurrence in adults ${ }^{18}$ and children with an abnormal EEG. ${ }^{20}$ Only 1 other study has analyzed status epilepticus as a risk factor, and, unlike the present study, this factor was not predictive of recurrence. ${ }^{20}$ No other studies have reported Todd's paresis to be a predictor. This finding is independent of neurologic examination.

Unlike the present study and the adult series of Hopkins et al, ${ }^{18}$ a partial seizure has been a predictor of recurrence in studies dealing exclusively with children ${ }^{17,20,21}$ and in the study of Annegers et al. ${ }^{16}$ Although we included subjects of all ages, only $23 \%$ of cases were under age 20 and most of these were teenagers. It is possible that children are different from adults in this respect. We do not find an abnormal neurologic examination to be a significant predictor of recurrence, although the point estimates of the risk are similar to those reported by Annegers et al. ${ }^{16}$ In agreement with 
several studies, neither age at 1st seizure nor sex were predictors. ${ }^{16,18,20}$

Although no studies published heretofor have been designed specifically to evaluate AED therapy, some analyses of the factor have invariably been attempted. No study has shown treatment to reduce recurrence risks, and in some, such as the present study, prescription of AED was associated with an increased recurrence risk even when controlling for other risk factors. This does not mean that medications are ineffective in the prevention of seizures: the data available are inadequate to determine whether the results are real or artifacts attributable to irregular medication use, inadequate or inappropriate AED, or AED withdrawal. The proper medication in the proper dose taken on a consistent basis is necessary to confirm or deny efficacy. In general, patients in the present study given AED were placed on low dosages, levels were not monitored or adjusted, and many did not take the medication on a regular basis if at all. The question of AED effect can only be addressed in a randomized clinical trial with careful monitoring of AED use in treated patients. ${ }^{24}$

\section{References}

1. Hauser WA. Should people be treated after a first seizure? Arch Neurol 1986;43:1287-1288.

2. Hart RG, Easton JD. Seizure recurrence after a first, unprovoked seizure. Arch Neurol 1986;43:1289-1290.

3. Hauser WA, Anderson VE, Loewenson RB, McRoberts SM. Seizure recurrence after a first unprovoked seizure. N Engl $J$ Med 1982;307:522-528.

4. Ewles RDC, Reynolds EH. Should people be treated after a first seizure? Arch Neurol 1988;45:490-491.

5. Commission on Classification and Terminology of the International League Against Epilepsy. Proposal for revised clinical and electroencephalographic classification of epileptic seizures. Epilepsia 1981;22:489-501.

6. Annegers JF, Grabow JD, Groover RV, Laws ER, Elveback LR,
Kurland LT. Seizures after head trauma: a population study. Neurology 1980;30:683-689.

7. Hauser WA, Ramirez-Lassepas M, Rosenstein R. Risk for seizures and epilepsy following cerebrovascular insults. Abstract. Epilepsia 1984;25:666.

8. Annegers JF, Nicolosi A, Beghi E, Hauser WA, Kurland LT. The risk of unprovoked seizures after encephalitis and meningitis. Neurology 1988;38:1407-1410.

9. Benedetti MD, Shinnar S, Cohen H, Inbar D, Hauser WA. Risk factors for epilepsy in children with cerebral palsy and/or mental retardation. Abstract. Epilepsia 1986;27:614.

10. Nelson KB, Ellenberg JH. Antecedents of seizure disorders in early childhood. Am J Dis Child 1986;140:1053-1061.

11. Cutler SJ, Ederer F. Maximum utilization of the life table method in analyzing survival. J Chronic Dis 1958;8:699-712.

12. Elandt-Johnson RC, Johnson NL. Survival models and data analysis. New York: John Wiley \& Sons, 1980:150-180.

13. Kaplan EL, Meier P. Nonparametric estimations from incomplete observation. J Am Stat Assoc 1958;53:457-481.

14. Cox DR. Regression models and life-tables. $J$ R Stat Soc [B] 1972;34:187-220.

15. Elwes RDC, Chesterman P, Reynolds EH. Prognosis after a first untreated tonic-clonic seizure. Lancet 1985;2:752-753.

16. Annegers JF, Shirts SB, Hauser WA, Kurland LT. Risk of recurrence after an initial unprovoked seizure. Epilepsia 1986;27:43-50.

17. Hirtz DB, Ellenberg JH, Nelson KB. The risk of recurrence of nonfebrile seizures in children. Neurology 1984;34:637-641.

18. Hopkins A, Garman A, Clarke C. The first seizure in adult life. Lancet 1988;1:721-726.

19. Cleland PG, Mosbue RJ, Steward WP, Fosta JB. Prognosis of isolated seizures in adult life. Br Med J 1981;283:1364.

20. Shinnar S, Berg D, Moshe SL, et al. The risk of seizure recurrence following a first unprovoked seizure in childhood: a prospective study. Pediatrics 1990;85:1076-1085.

21. Camfield PR, Camfield CS, Dooley JM, Tibbles JAR, Fung T, Garner B. Epilepsy after a first unprovoked seizure in childhood. Neurology 1985;35:1657-1660.

22. Goodridge DMG, Shorvon SD. Epileptic seizures in a population of 6000 . I. Demography, diagnosis and classification, and role of the hospital service. Br Med J 1983;287:641-644.

23. Hauser WA, Rich SS, Jacobs MP, Anderson VE. Patterns of seizure occurrence and recurrence risks in patients with newly diagnosed epilepsy. Abstract. Epilepsia 1983;24:516-517.

24. Mussico M. The effect of drug treatment on risk of recurrence after a first tonic clonic seizure: an Italian multicenter randomized trial. Abstract. Neurology 1989;39(suppl 1):148. 


\section{Neurology}

\section{Seizure recurrence after a 1st unprovoked seizure: An extended follow-up}

W. Allen Hauser, Stephen S. Rich, John F. Annegers, et al.

Neurology 1990;40;1163

DOI 10.1212/WNL.40.8.1163

\section{This information is current as of August 1, 1990}

\section{Updated Information \& \\ Services}

\section{Citations}

Permissions \& Licensing

Reprints including high resolution figures, can be found at: http://n.neurology.org/content/40/8/1163.full

This article has been cited by 20 HighWire-hosted articles: http://n.neurology.org/content/40/8/1163.full\#\#otherarticles

Information about reproducing this article in parts (figures,tables) or in its entirety can be found online at:

http://www.neurology.org/about/about_the_journal\#permissions

Information about ordering reprints can be found online:

http://n.neurology.org/subscribers/advertise

Neurology ${ }^{\circledR}$ is the official journal of the American Academy of Neurology. Published continuously since 1951, it is now a weekly with 48 issues per year. Copyright $(9) 1990$ by Edgell Communications, Inc.. All rights reserved. Print ISSN: 0028-3878. Online ISSN: 1526-632X.

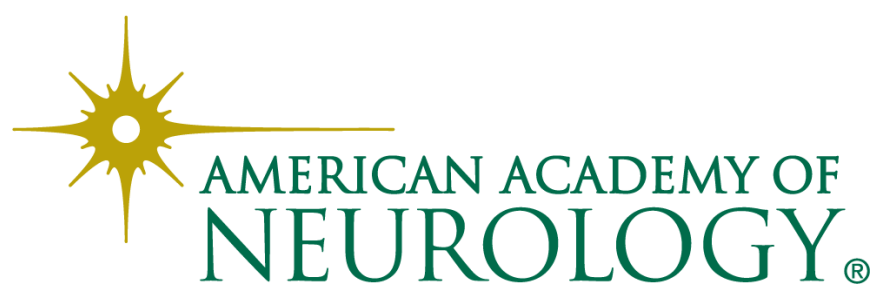

